\title{
The Lives We Invite To Flower Among Us Flower Beyond Us - Wendy Battin
}

For just as a wild animal, if it shall have escaped and thus recovered its natural liberty, is no longer the property of its captor, so also the sea may recover its possession of the shore.

- Hugo Grotius

So just as that wild animal, the sea,

is never in our midst, is constantly

our border, so also

a leopard, even in a zoo

escapes us. He prowls

all our city's avenues by pacing

cage corner to corner, even

when we are most vigilant.

Set him free on a beach.

A body in a halo of senses, he moves on the sand like water. The highest wave casts down the shore like a spotted cat.

Nothing, our oldest lesson save one, nothing is harder than water. The cat on flat beach, the cat with no tree, no ledge, as if caged,

cannot contain himself.

So also the thought containing the cat, set in motion in a woman's

mind, a word

in a halo of sense. She makes

the leopard dark avenues

into the city of men, and then

she makes the seventh wave,

ending in foam still short

of the body poured out on the sand.

But even when she is 
most circumspect, her mind cannot contain itself, as a vase

may hold a flower but may not hold

itself. She loses the word

that strokes her into sense, that moving cage and comfort.

The cat escapes

into the oldest lesson: no thing

is more yielding than water.

The woman rests

her mind in her body in

a halo of sense,

as if she were the sea, and continent. 